\title{
Sinonasal Phosphaturic Mesenchymal Tumor: A Rare and Misinterpreted Entity
}

\author{
Demetri Arnaoutakis ${ }^{1}$ Iman Naseri ${ }^{2}$
}

Address for correspondence Demetri Arnaoutakis, MD, Department of Otolaryngology-Head \& Neck Surgery, University of Texas Southwestern Medical Center, 5323 Harry Hines Blvd., Dallas, TX 75390, United States (e-mail: Takis.demetri@gmail.com).

J Neurol Surg Rep 2015;76:e233-e238.

\begin{abstract}
Keywords

- phosphaturic mesenchymal tumor

- skull base resection

- endoscopic sinus surgery

Objectives Oncogenic osteomalacia is a paraneoplastic syndrome in which the tumor secretes a peptide-like hormone, fibroblast growth factor, resulting in urinary loss of phosphates.

Methods We present the case of a 50-year-old woman with a benign phosphaturic mesenchymal tumor (PMT) involving the ethmoid sinus with obstruction of the ostiomeatal complex causing unilateral nasal airway obstruction.

Results The tumor was initially thought to be an esthesioneuroblastoma based on primary pathology interpretation and on clinical and radiographic appearance. However, a benign PMT was later confirmed by further testing.

Conclusion The tumor was removed entirely by the endoscopic transnasal approach, leading to a full resolution of symptoms.
\end{abstract}

\section{Introduction}

Phosphaturic mesenchymal tumors (PMTs) are very rare tumors frequently associated with oncogenic osteomalacia (OO), a paraneoplastic syndrome that manifests as renal phosphate wasting. The tumor cells produce a peptide hormonelike substance known as fibroblast growth factor 23 (FGF-23), a physiologic regulator of phosphate levels, originally called phosphatonin. ${ }^{1}$ It decreases proximal tubule reabsorption of phosphates and inhibits 1 - $\alpha$-hydroxylase enzyme, which reduces levels of $1-\alpha, 25$-dihydroxyvitamine D3. Thus overexpression of FGF-23 leads to increased clearance of phosphate in the urine, mobilization of calcium and phosphate from bone, and the reduction of osteoblastic activity causing osteomalacia. ${ }^{2}$

The patient typically presents with gradual muscular weakness and bone pain or pathologic fractures. The diagnosis is commonly delayed for years due to the nonspecific nature of these symptoms, failure to include serum phosphorus levels in routine blood chemistry testing, and difficulty in identifying the responsible tumor. Additionally, these tumors are often missed because of their rarity and histologic overlap with other mesenchymal neoplasms. ${ }^{3}$ Resolution of symptoms, however, does ensue following surgical excision of the neoplasm. We present a case of PMT involving the paranasal sinuses that clinically and radiographically resembled esthesioneuroblastoma (ENB).

\section{Case Report}

A 50-year-old woman was referred to the Division of Otolaryngology Head \& Neck Surgery at the University of Florida College of Medicine, Jacksonville, with a several month history of progressive right nasal airway obstruction. She was initially evaluated at an outside institution, and office endoscopic examination revealed a polypoid mass involving right nasal cavity. Her symptoms were right nasal airway obstruction along with midfacial pressure and pain. There were no symptoms associated with cranial nerve palsies, epistaxis, or visual deficits. She also complained of generalized weakness and joint pains previously thought to be arthritis. received

April 13, 2015

accepted after revision

June 28, 2015

published online

August 21, 2015
DOI http://dx.doi.org/

$10.1055 / \mathrm{s}-0035-1562852$. ISSN 2193-6366. (c) 2015 Georg Thieme Verlag KG
Stuttgart · New York

License terms

((1) $\circledast$ 
Endoscopic examination revealed a large polypoid mass emanating from the right middle meatus. There were no other pertinent endoscopic findings. The remainder of her physical examination was unremarkable. Notably, the patient reported an allergy to laundry and dishwashing detergents. Also, she noted that during her last pregnancy ( $>20$ years ago) she developed strange calcifications on her teeth that were removed by her dentist. After imaging, a biopsy of the right nasal mass was initially diagnosed as ENB. Computed tomography (CT) scan of the sinuses demonstrated opacification of the right frontal recess, middle meatus, and anterior ethmoid cells with abutment of the cribriform plate of ethmoid bone. Magnetic resonance imaging (MRI) confirmed the findings just described; together with the CT finding and biopsy diagnosis, the mass was highly suspicious for ENB ( - Fig. 1A, B).

The pathology specimen was further reviewed by an outside consultation, and special stains and molecular studies led to a final diagnosis of a benign PMT. This diagnosis was supported by positive tumor expression of FGF-23 detected by reverse transcription polymerase chain reaction and gel electrophoresis on RNA extracted from paraffin-embedded tissue ( - Fig. $2 A-C$ ). The patient was then referred to our institution for further management. She subsequently had endoscopic transnasal excision of the tumor in its entirety.

Intraoperatively, the tumor did not have any infiltrative components. The base origin of the tumor could not be identified because the mass was hyperemic and resembled the surrounding mucosa ( - Fig. 3). Although it was adherent to the normal mucosa, it was amenable to be dissected free of its surrounding normal tissue. The tumor was moderately vascularized and friable upon instrument manipulation. The superior extent of the tumor did not involve the olfactory mucosa and was dissected away from the region of the olfactory mucosa along the roof of the nasal cavity. Because
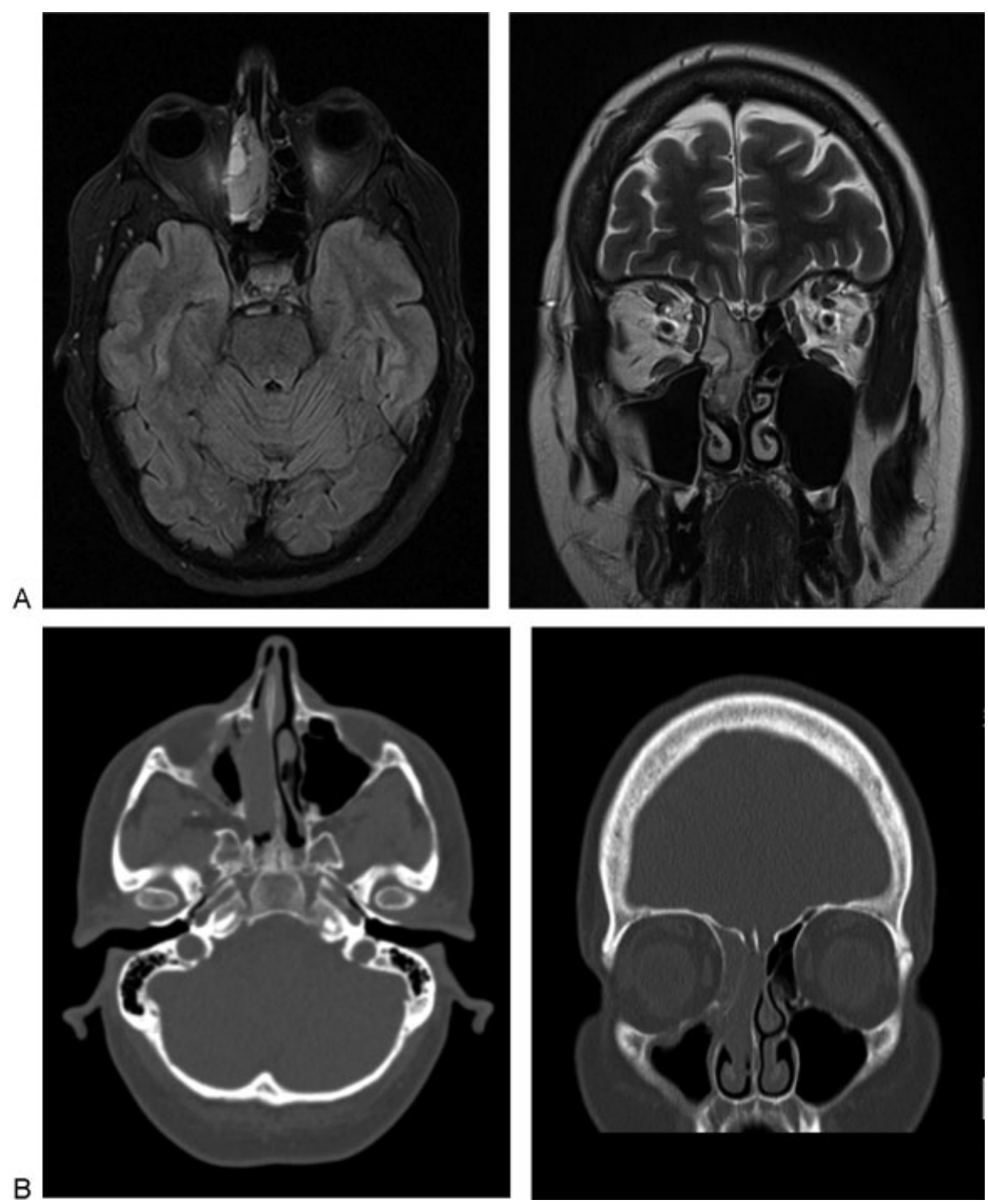

Fig. 1 (A) Axial and coronal magnetic resonance and (B) computed tomography images depicting the level of involvement within the right nasal and paranasal sinus cavities along with associated mass effect upon adjacent bony structures closely resembling an early stage esthesioneuroblastoma. 


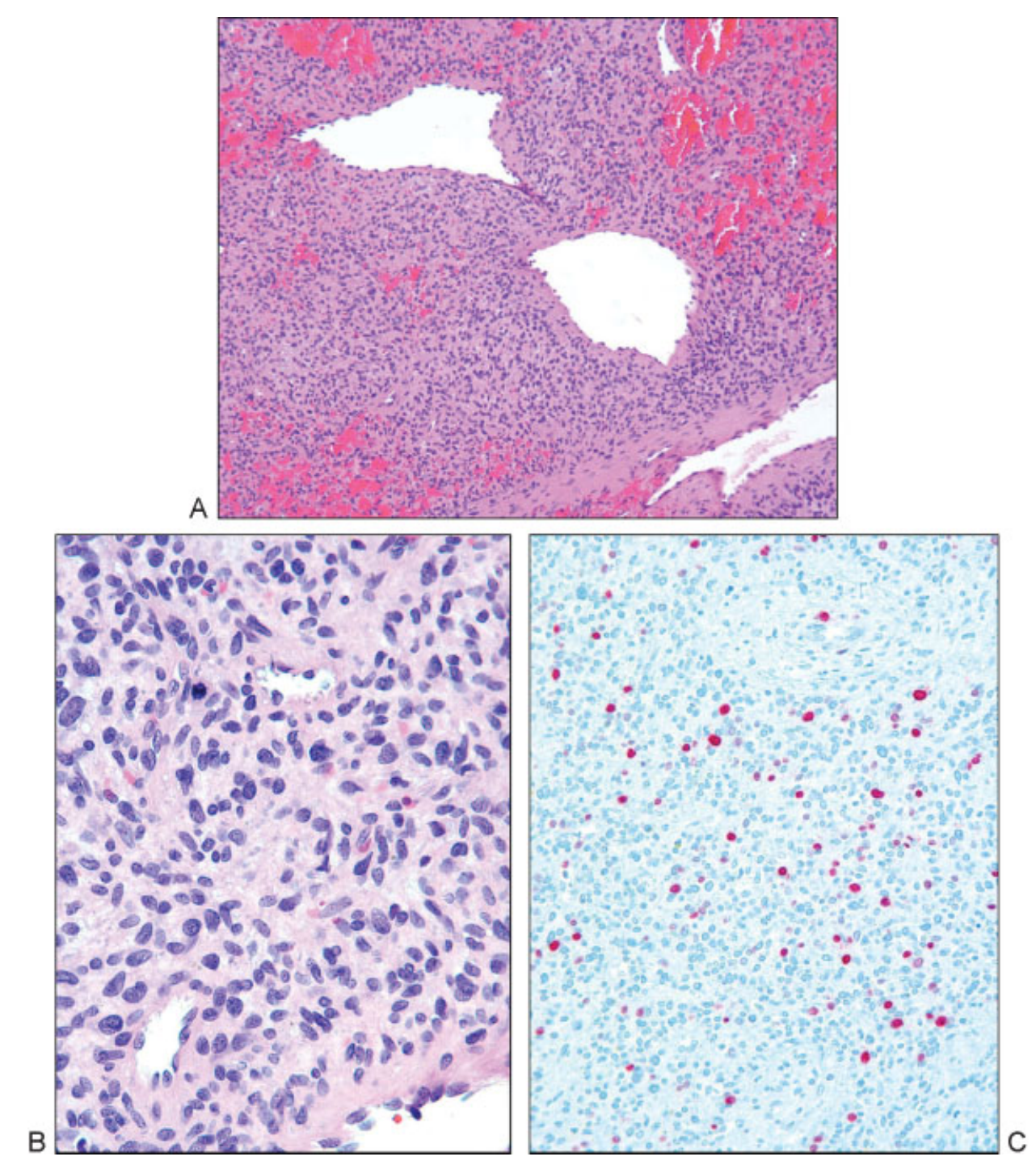

Fig. 2 Tumor histology revealing dense cellularity with hemangiopericytoma-like vessels (A), round to ovoid nuclei with a single mitosis (arrow), mild pleomorphism, granular chromatin, and inconspicuous nucleoli in a fibrillary stroma (B), and proliferation marker Ki-67 labeling $\sim 10 \%$ of tumor nuclei (C) (H\&E stain: A, $\times 10$; B, $\times 40$; and Ki-67 immunoperoxidase stain C, $\times 20$ ).

of the tumor's resemblance to the surrounding normal tissues, the mucosa was removed from bony structures within the right ostiomeatal unit and surrounding region to ensure complete resection. To preserve the function of the ostiomeatal unit, frontal, maxillary, total ethmoid, and sphenoidotomies were performed on the side of the tumor.

Histologically, the resected tumor was consistent with PMT, displaying moderate to dense cellularity with ill-defined cell borders, ovoid to round nuclei with granular chromatin, inconspicuous nucleoli, and focal nuclear pleomorphism. Thick and thin wall blood vessels were prominent with a hemangiopericytoma-like pattern. The tumor cells were negative for pancytokeratin AE1/AE3, NSE, neurofilament, chromogranin, synaptophysin, S100 protein, desmin, smooth muscle actin, and CD34 immunostains. The tumor lacked the characteristic "grungy" calcification described in PMT.

The patient had normal postoperative convalescence with full resolution of her initial presenting symptoms including the generalized weakness and joint pains. Unfortunately, her preoperative laboratory work-up only included basic profiles and did not include urine or serum phosphate levels. Serum 25-hydroxyvitamin D levels were low at $15 \mathrm{ng} / \mathrm{mL}$, serum alkaline phosphatase elevated at $224 \mathrm{IU} / \mathrm{L}$ (reference range: 44-147 IU/L), and urine phosphate levels slightly elevated at $5.1 \mathrm{mg} / \mathrm{dL}$ (reference range: $2.5-4.5 \mathrm{mg} / \mathrm{dL}$ ) in the immediate postoperative week. Testing for ANA, dsDNA, RNP, SSA, and SSB were all negative. The patient was referred to the rheumatology service for further evaluation and management. Additional diagnostic work-up has included a bone scan, revealing mild osteopenia. She is currently on oral vitamin D supplementation.

\section{Discussion}

The first case of OO was described by McCance in 1947, although the relationship between PMT and osteomalacia was not established until 1959 by Prader et al. ${ }^{4,5}$ More than 

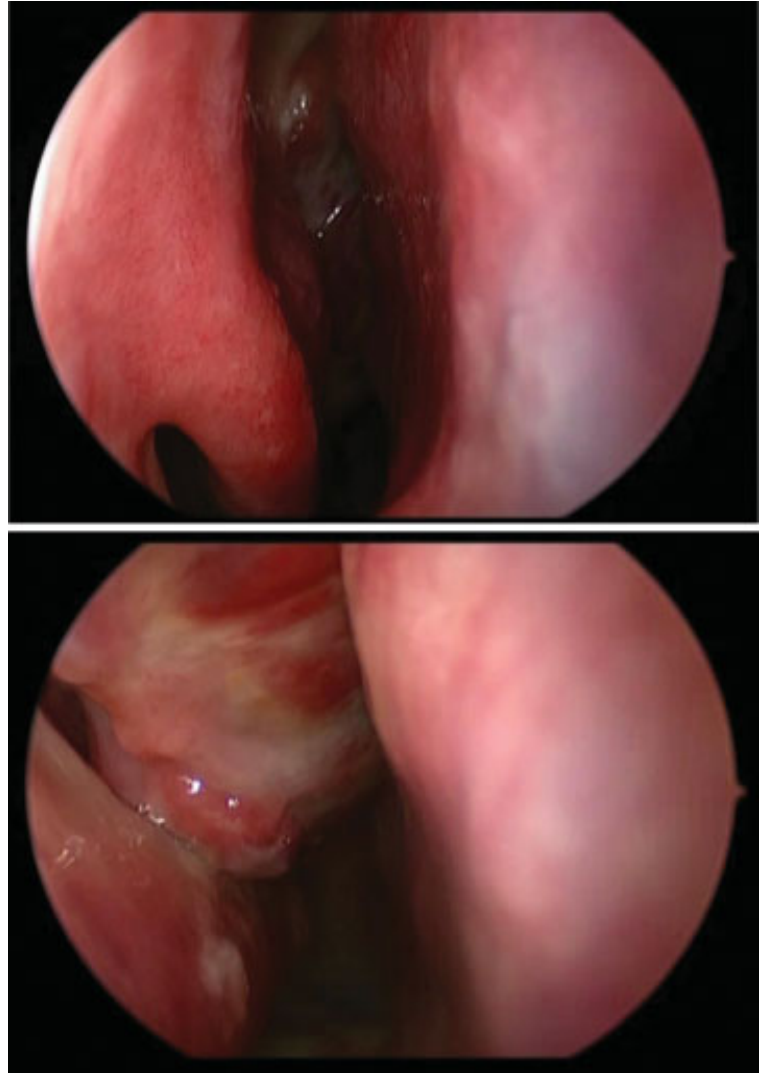

Fig. 3 Endoscopic intraoperative views of the tumor involving the nasal cavity (above) and closely associated with the middle turbinate both along the medial and lateral aspects (below).

100 cases have now been reported, although localization to the paranasal sinuses is extremely rare. Only 17 prior sinonasal cases have been reported in the literature and are outlined in - Table 1. ${ }^{6-37}$ Tumor-induced osteomalacia is typically caused by a wide range of benign and malignant mesenchymal tumors such as giant cell tumor, nonossifying fibroma, osteoblastoma, and chondroma. ${ }^{38}$

Diagnosis of tumor-induced osteomalacia continues to be a challenge because the symptoms are nonspecific. Typical time from the onset of symptoms to a presumptive diagnosis of tumor-induced osteomalacia is often $>2.5$ years. ${ }^{39}$ In this case, the patient did report progressive unilateral nasal obstruction, prompting an otolaryngology consultation and expeditious diagnostic work-up and treatment. The symptoms, along with endoscopic examination findings, initial pathology, and radiologic findings, were highly suggestive of the diagnosis of ENB, which can also be slow-growing tumors with similar nonspecific symptomatology. The gross appearance of the tumor may also be similar among ENBs and PMT, appearing as a polypoid mass on nasal endoscopy.

Imaging with CT and/or MRI cannot differentiate such tumors from others causing nasal obstruction but are useful for identifying the extent of involvement and the presence of locally invasive characteristics that can aid surgical planning and, in case of a malignancy like ENB, for tumor staging. Microscopically, the histologic tumor resemblance in our case to ENB on hematoxylin and eosin(H\&E)-stained sections suggested the initial misdiagnosis of ENB. ${ }^{40}$ However, the positive molecular studies for FGF-23 and lack of expression of neuronal markers (such as chromogranin, synaptophysin, neurofilament, and nonspecific esterase) in the tumor established the diagnosis of PMT. Indeed, the spectrum of histologic variation in PMT is wide and reflected by the variety of different initial diagnoses for these tumors such as osteosarcoma, mesenchymal chondrosarcoma, chondroblastoma, atypical enchondroma, spindle cell lipoma, angiolipoma, sclerosing hemangioma, hemangiopericytoma with osteoclast-like giant cells, tenosynovial giant cell tumors, and benign mesenchymal tumor among other diagnoses. ${ }^{41}$

Tumor-induced osteomalacia should be included in the differential diagnosis in patients with progressive weakness,

Table 1 Reported cases of head and neck phosphaturic mesenchymal tumor

\begin{tabular}{|c|c|c|c|}
\hline Study & Age, $y / \operatorname{Sex}$ & Tumor site & Presence of $\mathrm{OO}$ \\
\hline \multicolumn{4}{|l|}{ Sinonasal } \\
\hline Linsey et $\mathrm{al}^{6}$ & $54 / F$ & Nasopharynx & Yes \\
\hline Weidner and Santa Cruz ${ }^{7}$ & $35 / F$ & Maxillary sinus & Yes \\
\hline Papotti et $\mathrm{al}^{8}$ & $38 / \mathrm{F}$ & Maxillary sinus, ethmoid & Yes \\
\hline Gonzalez-Compta et al $^{9}$ & $69 / F$ & Ethmoids, maxillary and frontal & Yes \\
\hline Kawai et al ${ }^{10}$ & $53 / F$ & Ethmoids & Yes \\
\hline Ungari et al ${ }^{11}$ & $24 / \mathrm{M}$ & Ethmoids & Yes \\
\hline Inokuchi et al ${ }^{12}$ & $24 / F$ & Maxillary, ethmoids, and frontal & Yes \\
\hline 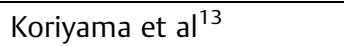 & $41 / F$ & Maxillary & Yes \\
\hline Pedrazzoli et al $^{14}$ & $37 / F$ & Maxillary & Yes \\
\hline \multirow[t]{2}{*}{ Shelekhova et al ${ }^{15}$} & $70 / F$ & Nasal cavity & Yes \\
\hline & $53 / \mathrm{M}$ & Frontal sinus & Yes \\
\hline Peterson et al ${ }^{16}$ & $33 / F$ & Maxillary sinus & Yes \\
\hline
\end{tabular}


Table 1 (Continued)

\begin{tabular}{|c|c|c|c|}
\hline Study & Age, $y /$ Sex & Tumor site & Presence of $\mathrm{OO}$ \\
\hline Parshwanath et al ${ }^{17}$ & $42 / \mathrm{F}$ & Nasal cavity, ethmoids & Yes \\
\hline Komínek et $\mathrm{al}^{18}$ & $53 / \mathrm{M}$ & Frontal sinus, ethmoids & No \\
\hline Guglielmi et al $^{19}$ & $22 / \mathrm{M}$ & Nasopharynx, ethmoids, sphenoids & Yes \\
\hline Battoo et $\mathrm{al}^{20}$ & $34 / F$ & Nasal cavity, ethmoids, maxillary & Yes \\
\hline Deep et $a^{21}$ & $41 / \mathrm{M}$ & Nasopharynx & No \\
\hline Okamiya et $\mathrm{al}^{22}$ & $35 / F$ & Ethmoid & Yes \\
\hline \multicolumn{4}{|c|}{ Non-sinonasal head and neck PMTs } \\
\hline Oleksky et $\mathrm{al}^{23}$ & $40 / \mathrm{M}$ & Pharynx & Yes \\
\hline Shenker and Grekin ${ }^{24}$ & $55 / \mathrm{M}$ & Neck & Yes \\
\hline Weidner and Santa Cruz ${ }^{7}$ & $27 / \mathrm{M}$ & Mandible & Yes \\
\hline Harvey et $\mathrm{al}^{25}$ & $32 / D$ & Thyroid & Yes \\
\hline Yang et $\mathrm{al}^{26}$ & $31 / F$ & Perimandibular soft tissue & Yes \\
\hline Reyes-Múgica et al ${ }^{27}$ & $9 / F$ & Perimandibular soft tissue & Yes \\
\hline Dupond et $\mathrm{al}^{28}$ & $71 / \mathrm{M}$ & Mandibular gingiva & Yes \\
\hline Woo et $\mathrm{al}^{29}$ & $42 / F$ & Mandible & Yes \\
\hline Kaylie et $\mathrm{al}^{30}$ & $46 / F$ & Temporal bone & Yes \\
\hline Uramoto et $\mathrm{al}^{31}$ & $48 / F$ & Tongue & Yes \\
\hline Yun et $a^{32}$ & $71 / \mathrm{F}$ & Floor of mouth & Yes \\
\hline Savage and Zimmer ${ }^{33}$ & $73 / F$ & Pterygopalatine fossa & Yes \\
\hline Mori et $\mathrm{al}^{34}$ & $42 / \mathrm{M}$ & Maxilla & Yes \\
\hline Sidell et $\mathrm{al}^{35}$ & $24 / F$ & Larynx & No \\
\hline Syed et $\mathrm{al}^{36}$ & NA & Temporal bone & No \\
\hline Luo et $\mathrm{al}^{37}$ & NA & Mandible & Yes \\
\hline
\end{tabular}

Abbreviations: NA, not applicable; OO, oncogenic osteomalacia; PMT, phosphaturic mesenchymal tumor.

bone and muscle pain, and pathologic fractures and alerts physicians to order serum/urine phosphorus panels. The finding of phosphaturia coupled with hypophosphatemia would instigate consideration of the potential causes of phosphate-wasting syndromes including PMT. Furthermore, the correct diagnosis of these tumors is important for several reasons. Severe bone demineralization may lead to pathologic fractures, resulting in permanent disability or rickets if occurring during infancy. Excess FGF-23 can lead to electrolyte imbalance, resulting in complications of several organs such as the heart, kidneys, and brain. In addition, making the correct diagnosis allows for implementation of the proper therapeutic approach. Definitive treatment in this case involved surgical excision with resolution of the patient's symptoms.

\section{Conclusion}

PMTs are rare underrecognized neoplasms that are frequently associated with $\mathrm{OO}$ through tumor elaboration of a phosphaturic hormone (FGF-23). Although these tumors may have distinct microscopic features, the wide spectrum of histologic variation in PMTs may lead to their misdiagnosis as a different tumor, thereby potentiating radically different treatment and unnecessary morbidity. A high level of clinical suspicion along with prompt biopsy and laboratory work-up to evaluate phosphate loss is vital for ensuring the correct diagnosis of PMT. This case highlights the close similarity between sinonasal ENB and PMT in both clinical presentation, imaging studies, and histology on H\&E stained sections. This is an important consideration because most of these tumors are benign, and complete resection cures intractable 00 when present.

\section{References}

1 Shimada T, Mizutani S, Muto T, et al. Cloning and characterization of FGF23 as a causative factor of tumor-induced osteomalacia. Proc Natl Acad Sci U S A 2001;98(11):6500-6505

2 Sundaram M, McCarthy EF. Oncogenic osteomalacia. Skeletal Radiol 2000;29(3):117-124

3 Reisacher WR, Pincus RL. Pathologic quiz case 1. Pneumocystic lymphadenitis. Arch Otolaryngol Head Neck Surg 1997;123(8): 880, 882-883

4 McCance RA. Osteomalacia with Looser's nodes (Milkman's syndrome) due to a raised resistance to vitamin $\mathrm{D}$ acquired about the age of 15 years. QJ Med 1947;16(1):33-46

5 Prader V. Rickets following bone tumor. [in German]. Helv Paediatr Acta 1959;14:554-565 
6 Linsey M, Smith W, Yamauchi H, Bernstein L. Nasopharyngeal angiofibroma presenting as adult osteomalacia: case report and review of the literature. Laryngoscope 1983;93(10):1328-1331

7 Weidner N, Santa Cruz D. Phosphaturic mesenchymal tumors. A polymorphous group causing osteomalacia or rickets. Cancer 1987;59(8):1442-1454

8 Papotti M, Foschini MP, Isaia G, Rizzi G, Betts CM, Eusebi V. Hypophosphatemic oncogenic osteomalacia: report of three new cases. Tumori 1988;74(5):599-607

9 Gonzalez-Compta X, Mañós-Pujol M, Foglia-Fernandez M, et al. Oncogenic osteomalacia: case report and review of head and neck associated tumours. J Laryngol Otol 1998;112(4):389-392

10 Kawai Y, Morimoto S, Sakaguchi K, et al. Oncogenic osteomalacia secondary to nasal tumor with decreased urinary excretion of cAMP. J Bone Miner Metab 2001;19(1):61-64

11 Ungari C, Rocchi G, Rinna C, Agrillo A, Lattanzi A, Pagnoni M. Hypophosphaturic mesenchymal tumor of the ethmoid associated with oncogenic osteomalacia. J Craniofac Surg 2004;15(3): 523-527

12 Inokuchi $\mathrm{G}$, Tanimoto $\mathrm{H}$, Ishida $\mathrm{H}$, et al. A paranasal tumor associated with tumor-induced osteomalacia. Laryngoscope 2006;116(10):1930-1933

13 Koriyama N, Nishimoto K, Kodama T, et al. Oncogenic osteomalacia in a case with a maxillary sinus mesenchymal tumor. Am J Med Sci 2006;332(3):142-147

14 Pedrazzoli M, Colletti G, Ferrari M, Rossetti G, Moneghini L, Autelitano L. Mesenchymal phosphaturic neoplasm in the maxillary sinus: a case report. Int J Oral Maxillofac Surg 2010;39(10): 1027-1032

15 Shelekhova KV, Kazakov DV, Michal M. Sinonasal phosphaturic mesenchymal tumor (mixed connective tissue variant): report of 2 cases. Am J Surg Pathol 2010;34(4):596-597

16 Peterson NR, Summerlin DJ, Cordes SR. Multiple phosphaturic mesenchymal tumors associated with oncogenic osteomalacia: case report and review of the literature. Ear Nose Throat J 2010; 89(6):E11-E15

17 Parshwanath HA, Kulkarni PR, Rao R, Joshi SK, Patil P. Phosphaturic mesenchymal tumor of ethmoid sinus. Indian J Pathol Microbiol 2010;53(2):384-385

18 Komínek P, Stárek I, Geierová M, Matoušek P, Zeleník K. Phosphaturic mesenchymal tumour of the sinonasal area: case report and review of the literature. Head Neck Oncol 2011;3:16

19 Guglielmi G, Bisceglia M, Scillitani A, Folpe AL. Oncogenic osteomalacia due to phosphaturic mesenchymal tumor of the craniofacial sinuses. Clin Cases Miner Bone Metab 2011;8(2):45-49

20 Battoo AJ, Salih S, Unnikrishnan AG, et al. Oncogenic osteomalacia from nasal cavity giant cell tumor. Head Neck 2012;34(3): 454-457

21 Deep NL, Cain RB, McCullough AE, Hoxworth JM, Lal D. Sinonasal phosphaturic mesenchymal tumor: case report and systematic review. Allergy Rhinol (Providence) 2014;5(3):162-167

22 Okamiya T, Takahashi K, Kamada H, et al. Oncogenic osteomalacia caused by an occult paranasal sinus tumor. Auris Nasus Larynx 2015;42(2):167-169

23 Olefsky J, Kempson R, Jones H, Reaven G. "Tertiary" hyperparathyroidism and apparent "cure" of vitamin-D-resistant rickets after removal of an ossifying mesenchymal tumor of the pharynx. N Engl J Med 1972;286(14):740-745

24 Shenker Y, Grekin RJ. Oncogenic osteomalacia. Isr J Med Sci 1984; 20(8):739-741

25 Harvey JN, Gray C, Belchetz PE. Oncogenous osteomalacia and malignancy. Clin Endocrinol (Oxf) 1992;37(4):379-382

26 Yang IM, Park YK, Hyun YJ, et al. Oncogenic osteomalacia caused by a phosphaturic mesenchymal tumor of the oral cavity: a case report. Korean J Intern Med 1997;12(1):89-95

27 Reyes-Múgica M, Arnsmeier SL, Backeljauw PF, Persing J, Ellis B, Carpenter TO. Phosphaturic mesenchymal tumor-induced rickets. Pediatr Dev Pathol 2000;3(1):61-69

28 Dupond JL, Mahammedi H, Prié D, et al. Oncogenic osteomalacia: diagnostic importance of fibroblast growth factor 23 and F-18 fluorodeoxyglucose PET/CT scan for the diagnosis and follow-up in one case. Bone 2005;36(3):375-378

29 Woo VL, Landesberg R, Imel EA, et al. Phosphaturic mesenchymal tumor, mixed connective tissue variant, of the mandible: report of a case and review of the literature. Oral Surg Oral Med Oral Pathol Oral Radiol Endod 2009;108(6):925-932

30 Kaylie DM, Jackson CG, Gardner EK. Oncogenic osteomalacia caused by phosphaturic mesenchymal tumor of the temporal bone. Otolaryngol Head Neck Surg 2006;135(4):653-654

31 Uramoto N, Furukawa M, Yoshizaki T. Malignant phosphaturic mesenchymal tumor, mixed connective tissue variant of the tongue. Auris Nasus Larynx 2009;36(1):104-105

32 Yun KI, Kim DH, Pyo SW. A phosphaturic mesenchymal tumor of the floor of the mouth with oncogenic osteomalacia: report of a case. J Oral Maxillofac Surg 2009;67(2):402-405

33 Savage CR, Zimmer LA. Oncogenic osteomalacia from pterygopalatine fossa mass. J Laryngol Otol 2009;123(9):1052-1054

34 Mori Y, Ogasawara T, Motoi T, et al. Tumor-induced osteomalacia associated with a maxillofacial tumor producing fibroblast growth factor 23: report of a case and review of the literature. Oral Surg Oral Med Oral Pathol Oral Radiol Endod 2010;109(3):e57-e63

35 Sidell D, Lai C, Bhuta S, Barnes L, Chhetri DK. Malignant phosphaturic mesenchymal tumor of the larynx. Laryngoscope 2011; 121(9):1860-1863

36 Syed MI, Chatzimichalis M, Rössle M, Huber AM. Recurrent phosphaturic mesenchymal tumour of the temporal bone causing deafness and facial nerve palsy. J Laryngol Otol 2012;126(7):721-724

37 Luo L, Low N, Vandervord J. Mandibular phosphaturic mesenchymal tumor-mixed connective tissue variant in a young girl. Cleft Palate Craniofac J 2013;50(6):751-753

38 Schapira D, Ben Izhak O, Nachtigal A, et al. Tumor-induced osteomalacia. Semin Arthritis Rheum 1995;25(1):35-46

39 Ruppe MD, Jan de Beur SM. Disorders of phosphate homeostasis. In: Rosen CJ, ed. Primer of the metabolic bone diseases and disorders of mineral metabolism. 6th ed. Washington, DC: American Society for Bone and Mineral Research; 2006

40 Dulguerov P, Calcaterra T. Esthesioneuroblastoma: the UCLA experience 1970-1990. Laryngoscope 1992;102(8):843-849

41 Folpe AL, Fanburg-Smith JC, Billings SD, et al. Most osteomalaciaassociated mesenchymal tumors are a single histopathologic entity: an analysis of 32 cases and a comprehensive review of the literature. Am J Surg Pathol 2004;28(1):1-30 